\title{
Probióticos do gênero Bacillus em dietas para pós-larvas de tilápia do Nilo
}

\section{(Oreochromis niloticus)}

\author{
Probiotics of the gender Bacillus in diets for Nil tilapia post-larves (Oreochromis niloticus) \\ Probióticos del género Bacillus en dietas para post-larvas de tilápia del Nilo (Oreochromi sniloticus)
}

Recebido: 10/06/2021 | Revisado: 17/06/2021 | Aceito: 19/06/2021 | Publicado: 02/07/2021

Valdir Silva de Castro

ORCID: https://orcid.org/0000-0002-7816-8351 Universidade Estadual do Oeste do Paraná, Brasil E-mail:valdircastro8@Gmail.com

Débora Tatyane Oliveira Xavier ORCID: https://orcid.org/0000-0003-3571-6626 Universidade Estadual do Oeste do Paraná, Brasil E-mail: debora@coodersus.com.br

Antonio Francisco Campanha da Silva

ORCID: https://orcid.org/0000-0001-7513-2890 Universidade Estadual do Oeste do Paraná, Brasil E-mail: franciscroyff@hotmail.com José Rafael Soares Fonseca ORCID: https://orcid.org/0000-0003-1934-333X Universidade Estadual do Oeste do Paraná, Brasil E-mail: ra.phb@hotmail.com

Wilson Rogério Boscolo

ORCID: https://orcid.org/0000-0002-1808-0518 Universidade Estadual do Oeste do Paraná, Brasil E-mail: wilsonboscolo@hotmail.com

Aldi Feiden

ORCID: https://orcid.org/0000-0002-6823-9291 Universidade Estadual do Oeste do Paraná, Brasil E-mail: aldifeiden@gmail.com

Altevir Signor

ORCID: https://orcid.org/0000-0002-4659-6466 Universidade Estadual do Oeste do Paraná, Brasil E-mail: altevir.signor@gmail.com

Arcangelo Augusto Signor

ORCID: https://orcid.org/0000-0003-4686-3488 Instituto Federal do Paraná, Brasil E-mail: arcangelo.signor@ifpr.edu.br

\section{Resumo}

Com o objetivo de avaliar diferentes níveis de probiótico em dietas para pós-larvas de tilápia do Nilo, 1.680 póslarvas de tilápia do Nilo $(0,05 \pm 0,01 \mathrm{~g})$ foram distribuídos em 24 aquários de $110 \mathrm{~L}$, em um delineamento inteiramente casualizado com seis tratamentos e quatro repetições, considerando como unidade experimental um aquário com 70 alevinos. Durante o experimento foram monitorados diariamente os parâmetros de qualidade de água utilizando sonda multiparâmetro portátil sendo avaliado a temperatura da água $\left(26,9 \pm 0,5^{\circ} \mathrm{C}\right)$, oxigênio dissolvido $(4,0 \pm 0,7 \mathrm{mg} / \mathrm{L})$, condutividade elétrica $(170,1 \pm 46,6 \mu \mathrm{S} / \mathrm{cm})$ e $\mathrm{pH}(7,2 \pm 0,5)$. Foi formulada uma dieta basal (controle - 0,00) e realizado níveis de inclusão de probiótico do gênero Bacillus 4,0x 10 ${ }^{12}$ UFC (0,02; 0,04; 0,$06 ; 0,08 ; 0,10 \mathrm{~g} / 100 \mathrm{~g}$ ) de ração. Ao final, foram avaliados os parâmetros de desempenho zootécnico e composição centesimal da carcaça, onde não foi observada diferenças $(\mathrm{P}<0,05)$ sobre os parâmetros avaliados. Foi realizada histologia do intestino, e as medidas as altura e largura dos vilos e espessura da túnica, onde observou-se influência $(\mathrm{P}<0,05)$ sobre a largura dos vilose espessura da túnica, que apresentaram melhores respostas nos níveis de inclusões mais elevado de probióticos $(0,08$ e $0,10 \mathrm{~g})$. Apesar de, não haver influência positiva dos níveis de inclusão de probiótico do gênero Bacillus na dieta não influenciarem no desempenho zootécnico da tilápia do Nilo, recomenda-se a inclusão de $0,08 \mathrm{~g} / \mathrm{kg}$ de probiótico do gênero Bacillus por apresentar melhora na saúde intestinal das pós-larvas de tilápia do Nilo.

Palavras-chave: Aquicultura; Alimento alternativo; Nutrição; Probióticos.

\section{Abstract}

In order to evaluate different levels of probiotic in diets for Nile tilapia post-larvae, 1,680 Nile tilapia postlarvae $(0.05 \pm 0.01 \mathrm{~g})$ were distributed in $24110 \mathrm{~L}$ aquariums, in a completely randomized design with six treatments and four replications, considering as an experimental unit an aquarium with 70 fry. During the 
experiment, water quality parameters were monitored daily using a portable multiparameter probe and the water temperature $\left(26.9 \pm 0.5^{\circ} \mathrm{C}\right)$, dissolved oxygen $(4.0 \pm 0.7 \mathrm{mg} / \mathrm{L})$, electrical conductivity were evaluated. (170.1 $\pm 46.6 \mu \mathrm{S} / \mathrm{cm})$ and $\mathrm{pH}(7.2 \pm 0.5)$. A basal diet (control - 0.00) was formulated and levels of inclusion of probiotic of the genus Bacillus 4.0x $1012 \mathrm{CFU}(0.02 ; 0.04 ; 0.06 ; 0.08 ; 0.10 \mathrm{~g} / 100 \mathrm{~g}$ ) were performed) of feed. At the end, the parameters of zootechnical performance and centesimal composition of the carcass were evaluated, where no differences were observed $(\mathrm{P}<0.05)$ on the evaluated parameters. Bowel histology was performed, and the height and width of the villi and thickness of the tunic were measured, where influence $(\mathrm{P}$ $<0.05)$ on the width of the villi and tunic thickness was observed, which showed better responses in the levels of inclusions. higher probiotics $(0.08$ and $0.10 \mathrm{~g})$. Although, there is no positive influence of the levels of inclusion of probiotic of the genus Bacillus in the diet do not influence the zootechnical performance of Nile tilapia, it is recommended to include $0.08 \mathrm{~g} / \mathrm{kg}$ of probiotic of the genus Bacillus for presenting improvement in intestinal health of Nile tilapia post-larvae.

Keywords: Aquaculture; Alternative food; Nutrition; Probiotics.

\section{Resumen}

Para evaluar diferentes niveles de probióticos en dietas para post-larvas de tilapia del Nilo, se distribuyeron 1.680 post-larvas de tilapia del Nilo $(0.05 \pm 0.01 \mathrm{~g})$ en 24 acuarios de $110 \mathrm{~L}$, en un diseño completamente al azar con seis tratamientos y cuatro repeticiones, considerando como unidad experimental un acuario con 70 alevines. Durante el experimento, se monitorearon diariamente los parámetros de calidad del agua utilizando una sonda multiparamétrica portátil y se evaluó la temperatura del agua $\left(26.9 \pm 0.5^{\circ} \mathrm{C}\right)$, oxígeno disuelto $(4.0 \pm 0.7 \mathrm{mg} /$ $\mathrm{L})$, conductividad eléctrica $(170.1 \pm 46.6 \mu \mathrm{S} / \mathrm{cm}))$ y $\mathrm{pH}(7,2 \pm 0,5)$. Se formuló una dieta basal (control - 0.00) y se realizaron niveles de inclusión de probiótico del género Bacillus 4.0x 1012 UFC (0.02; 0.04; 0.06; 0.08; $0.10 \mathrm{~g} / 100 \mathrm{~g}$ ) de alimento. Al final, se evaluaron los parámetros de comportamiento zootécnico y composición centesimal de la canal, donde no se observaron diferencias $(\mathrm{P}<0.05)$ sobre los parámetros evaluados. Se realizó histología intestinal y se midió el alto y ancho de las vellosidades y el grosor de la túnica, donde se observó influencia ( $\mathrm{P}<0.05)$ en el ancho de las vellosidades y el grosor de la túnica, que mostró mejores respuestas en los niveles de inclusiones. probióticos superiores $(0,08$ y 0,10 g). Si bien, no existe influencia positiva de los niveles de inclusión de probióticos del género Bacillus en la dieta, no influyen en el desempeño zootécnico de la tilapia del Nilo, se recomienda incluir $0.08 \mathrm{~g} / \mathrm{kg}$ de probiótico del género Bacillus por presentar mejoría en salud intestinal de las post-larvas de tilapia del Nilo.

Palabras clave: Acuicultura; Alimentos alternativos; Nutrición; Probióticos.

\section{Introdução}

O cultivo intensivo com a melhoria das técnicas sustentáveis modernas contribui para reduzir a pressão sobre os estoques naturais, aumentando o abastecimento de pescado de boa qualidade nutricional e protéica para o consumo humano, bem como aumentar a confiabilidade do consumidor por sua vez mais exigente (Ibrahem, 2013; De Melo Lima et al., 2018). A intensificação ao longo de algumas décadas no setor aquícola vem sofrendo inúmeras mudanças para atender ao crescente consumo de pescado, as produções estão cada vez mais intensivas e com sucessivo uso de dietas balanceadas que atendam a exigência dos animais cada vez mais especifica, com aplicações de aditivos que promovam elevado crescimento (Nayak, 2010). O uso de probióticos e o manejo de doenças na aquicultura, com referência especial na piscicultura tem sido discutido e revisado por (Kesarcodi-Watson et al., 2008).

Suplementações alimentares à base de probióticos podem ser consideradas como sendo um conjunto de seres vivos que tem a capacidade de colonizar e multiplicar-se no intestino dos animais, equilibrando a microbiota e melhorando a absorção de nutrientes nos hospedeiros (Fuller, 1989; Mello et al., 2013). Probiótico é um promotor que confere ações benéficas para os peixes com diferentes modos de ação ao hospedeiro. Na aquicultura tem sido considerada como uma boa estratégia sustentável, pois controla patógenos que provocam doenças, mas também na nutrição, crescimento e saúde (Lazado \& Caipang, 2014a; Batista et al., 2016). A ocorrência de stress é verificada por meio de manejo a ser aplicada na piscicultura, representada por maior evidencia na manipulação excessiva de transporte de peixes na intensificação que favorecem ao meio de cultivo uma condição que enfraquece o sistema imunitário que conduz a uma maior susceptibilidade a doenças e patógenos (Sado-Yuji et al., 2014; Dawood et al., 2016; De Melo Lima et al., 2018). 
O surgimento de doenças é principalmente devido ao desequilíbrio de condições ambientais composta por patógeno, hospedeiro considerado um problema emergente limitando o crescimento da atividade, uma vez que implicam grandes mortalidades e consequentemente, perdas de cunho econômico (Dos Santos Júnior et al., 2016; De Melo Lima et al., 2018). No ambiente aquático os peixes estão em contato direto com concentrações elevadas de bactérias e vírus, em sua maioria são saprófagos e alguns patógenos ( $\mathrm{Li}$ et al., 2019). O uso de probióticos em rações para a suinocultura, avicultura e piscicultura existe há várias décadas e as pesquisas demonstram várias respostas positivas com a oferta deste aditivo como fonte dietética (Cavalheiro et al., 2014).

No mercado podem-se encontrar comercialmente vários tipos de probióticos na forma de emulsões líquidas, liofilizadas, liofilizadas-protegidas por microencapsulados, essas bactérias probióticas podem suportar elevadas temperaturas no processamento de ração entre $130-150^{\circ} \mathrm{C}$ extrusão, com pressão entorno de 30 a 60 atm (Vieira et al., 2005). A inclusão de bactérias probióticas na dieta de peixes pode ser realizada misturando-se, tanto, o pó probiótico liofilizado na ração na forma farelada/triturada para alimentar larvas e pós-larvas, como também misturada antes ou depois da peletização, em que não haja temperaturas superiores a $60^{\circ} \mathrm{C}$, no processamento de rações com probióticos liofilizadas não protegidas (Nakandakare et al., 2013).

No intestino de animais podem ocorrer desequilíbrios de aspectos químicos e físicos sendo considerados como mecanismos antibacterianos, que devem ser avaliados para que o desenvolvimento dessas bactérias benéficas possa colonizar e realizar maior eficiência na absorção dos alimentos (Fuller, 1989; Marengoni et al., 2015).

Linh et al. (2018) avaliaram em seu estudo as propriedades probióticas de Lactobacillus lactis para aplicação em aquicultura a partir de vegetais fermentados e com a investigação descobriram a sua eficácia contra as bactérias Grampositivas e bactérias patogénicas Gram-negativas. A flora microbiana a base de probióticos que colonizam o intestino de peixes desempenha um papel importante para a colonização do intestino por agentes patogénicos (Manzano et al., 2012).

Os primeiros probióticos encontrados foram às bactérias Lactobacillus. sp., que produzem ácido láctico e possuem grande aplicação em suplementação animal (Sahu et al., 2008). O gênero Bacillus, tem sido utilizado como fonte de incorporação em dietas, por ter boas características, como resistência ao calor e pressão. Suas enzimas possuem grande eficiência em degradação de carboidratos, lipídios e proteínas, gerando maior disponibilidade para absorção no intestino dos organismos aquáticos (Ochoa-Solano et al., 2006).

Entre as várias definições os estudos têm uma linha de raciocínio muito próximo, culminam com a afirmação de que os probióticos são organismos vivos que são administrados por via oral e traz benefícios para a saúde do animal de interesse (Dos Santos Júnior et al., 2016; Newaj-Fyzul et al., 2014; Ibrahem, 2015; Iribarren et al., 2012; Nayak, 2010; De Melo Lima et al., 2018), e que tem demostrado grande viabilidade econômica em cultivos, com o intuído de substituir agentes nocivos antibióticos que são aplicados em elevadas concentrações discriminadamente na aquicultura (Ferreira et al., 2015; Doroteo, 2018), e que possuem grande importância em uma aquicultura sustentável e ecológica (Cornélio et al., 2013; Lazado \& Ciapang, 2014b). Neste sentido, o objetivo de avaliar diferentes níveis de probiótico em dietas para pós-larvas de tilápia do Nilo.

\section{Metodologia}

O estudo foi realizado no Laboratório de Aquicultura do Grupo de Estudo em Manejo na Aquicultura (GEMAq), na Universidade Estadual do Oeste do Paraná-Unioeste, Campus de Toledo, no período de janeiro a fevereiro de 2019, com duração de 45 dias.

Para a experimentação animal foi aprovado (protocolo nº1-19) pelo Comitê de Ética no Uso de Animais (CEUA) UNIOESTE, atendendo ao Conselho Nacional de Controle de Experimentação Animal (CONCEA). 
O probiótico concentrado liofilizado aplicado, era formado por um mix de Bacillus cereus var. toyoi 4,0x10 ${ }^{12}$ UFC e

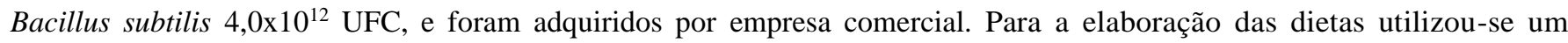
sistema computacional SuperCrac 6.1 Premium, seguindo a exigência nutricional da espécie, com base no (NRC 2011).

As rações continham a inclusão (controle - 0,00;0,02;0,04;0,06;0,08 e 0,10 g/100g) de concentrado de probiótico do gênero Bacillus 4,0x10 12 UFC na forma liofilizada na ração. Inicialmente, os macros ingredientes (Tabela 1) foram moídos em peneira 0,6mm e posteriormente foram moídos em 0,3mm e processado de acordo com Hayashi et al.(1999) e submetidos extrusão em extrusora EX-Micro. Para realizar a mistura do probiótico, foi utilizado como veículo o óleo de soja calculado da formulação e posteriormente homogeneizado no misturador em formato de $\mathrm{Y}$ por 5 minutos, na forma farelada e microextrusada.

Tabela 1. Formulação das dietas utilizadas no experimento de desempenho produtivo de pós-larvas de tilápia do Nilo.

\begin{tabular}{|c|c|c|c|c|c|c|}
\hline \multirow[b]{2}{*}{ Ingredientes } & \multicolumn{6}{|c|}{ Níveis de probióticos (g/100g) } \\
\hline & Controle & 0,02 & 0,04 & 0,06 & 0,08 & 0,10 \\
\hline Farelo de soja $(45 \%)$ & 49,22 & 49,22 & 49,22 & 49,22 & 49,22 & 49,22 \\
\hline $\begin{array}{l}\text { Peixe farinha tilápia }(58 \%) \\
\text { Arroz quirera }\end{array}$ & $\begin{array}{l}23,78 \\
13,43\end{array}$ & $\begin{array}{l}23,78 \\
13,43\end{array}$ & $\begin{array}{l}23,78 \\
13,43\end{array}$ & $\begin{array}{l}23,78 \\
13,43\end{array}$ & $\begin{array}{l}23,78 \\
13,43\end{array}$ & $\begin{array}{l}23,78 \\
13,43\end{array}$ \\
\hline Milho glúten (60\%) & 8,16 & 8,16 & 8,16 & 8,16 & 8,16 & 8,16 \\
\hline Probiótico $^{1}$ & 0,00 & 0,02 & 0,04 & 0,06 & 0,08 & 0,10 \\
\hline Óleo de soja & 3,39 & 3,39 & 3,39 & 3,39 & 3,39 & 3,39 \\
\hline Supl. mineral e vit. ${ }^{2}$ & 1,00 & 1,00 & 1,00 & 1,00 & 1,00 & 1,00 \\
\hline Cloreto de sódio & 0,50 & 0,50 & 0,50 & 0,50 & 0,50 & 0,50 \\
\hline Vitamina $\mathbf{C}$ & 0,20 & 0,20 & 0,20 & 0,20 & 0,20 & 0,20 \\
\hline Cloreto de colina & 0,15 & 0,15 & 0,15 & 0,15 & 0,15 & 0,15 \\
\hline Propianoto de cálcio & 0,10 & 0,10 & 0,10 & 0,10 & 0,10 & 0,10 \\
\hline BHT & 0,02 & 0,02 & 0,02 & 0,02 & 0,02 & 0,02 \\
\hline L-treonina & 0,04 & 0,04 & 0,04 & 0,04 & 0,04 & 0,04 \\
\hline Fosfato bicálcico & 0,01 & 0,01 & 0,01 & 0,01 & 0,01 & 0,01 \\
\hline \multicolumn{7}{|c|}{ Níveis nutricionais } \\
\hline Proteína bruta (\%) & 42,12 & 42,12 & 42,12 & 42,12 & 42,12 & 42,12 \\
\hline Proteína digestível (\%) & 38,60 & 38,60 & 38,60 & 38,60 & 38,60 & 38,60 \\
\hline Ed. tilápia (kcal/kg) & 3500,00 & 3500,00 & 3500,00 & 3500,00 & 3500,00 & 3500,00 \\
\hline Amido (\%) & 17,38 & 17,38 & 17,38 & 17,38 & 17,38 & 17,38 \\
\hline Arginina total $(\%)$ & 3,01 & 3,01 & 3,01 & 3,01 & 3,01 & 3,01 \\
\hline Cálcio (\%) & 2,00 & 2,00 & 2,00 & 2,00 & 2,00 & 2,00 \\
\hline Fibra bruta (\%) & 2,77 & 2,77 & 2,77 & 2,77 & 2,77 & 2,77 \\
\hline Fenilalanina total $(\%)$ & 2,04 & 2,04 & 2,04 & 2,04 & 2,04 & 2,04 \\
\hline Fósforo total (\%) & 1,00 & 1,00 & 1,00 & 1,00 & 1,00 & 1,00 \\
\hline Gordura (\%) & 6,91 & 6,91 & 6,91 & 6,91 & 6,91 & 6,91 \\
\hline Histidina total (\%) & 0,98 & 0,98 & 0,98 & 0,98 & 0,98 & 0,98 \\
\hline Isoleucina total (\%) & 1,78 & 1,78 & 1,78 & 1,78 & 1,78 & 1,78 \\
\hline Leucina total (\%) & 3,61 & 3,61 & 3,61 & 3,61 & 3,61 & 3,61 \\
\hline Lisina total (\%) & 2,34 & 2,34 & 2,34 & 2,34 & 2,34 & 2,34 \\
\hline Metionina total (\%) & 0,75 & 0,75 & 0,75 & 0,75 & 0,75 & 0,75 \\
\hline Treonina total $(\%)$ & 1,70 & 1,70 & 1,70 & 1,70 & 1,70 & 1,70 \\
\hline Triptofano total (\%) & 0,45 & 0,45 & 0,45 & 0,45 & 0,45 & 0,45 \\
\hline Valina total (\%) & 1,95 & 1,95 & 1,95 & 1,95 & 1,95 & 1,95 \\
\hline
\end{tabular}




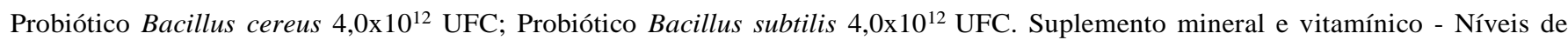
garantia por quilograma do produto: Vit. A, 1.750.000UI; Vit. D3, 375.000UI; Vit. E, 20.000UI; Vit. K3, 500mg; Vit. B1, 2.000mg; Vit.B2, 2.500mg; Vit.B6, 2.500mg; Vit. B12, 5.000mg; Ac. Folico, 625mg; Pantotenato Ca, 7.500mg; Vit. C, 37.500mg; Biotina, 50mg; Inositol, 12.500mg; Niacina, 8.750mg; Co, 50mg; Cu, 1.250mg; Fe, 15.000mg; I, 100mg; Mn, 3.750mg; Se, 75mg; Zn, $17.500 \mathrm{mg}$. Fonte: Autores.

As rações foram ofertadas em três fases: Fase I - ração farelada nos primeiros 15 dias, sendo que primeiramente foi extrusada e posteriormente triturada para que não haver-se seletividade de partículas quando ofertado; Fase IIalimentação com ração farelada e microextrusada para fazer uma transição alimentar em 10 dias para ração extrusada; e Fase III - ração microextrusada até o término do cultivo experimental 20 dias.

Foram alojadas 1.680 pós-larvas de tilápia do Nilo (Oreochromis niloticus), com peso médio inicial de

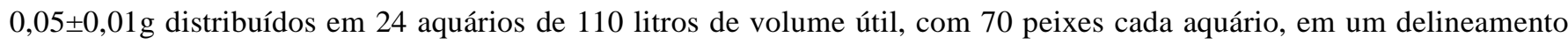
inteiramente casualizado com seis tratamentos e quatro repetições, considerando como unidade experimental o aquário com 70 pós-larvas.

Sistema de recirculação de água, com renovação de $0.001 \mathrm{~m}^{3} / \mathrm{s}$ e drenagem com cano de PVC de $40 \mathrm{~mm}$, com fonte de oxigenação continua promovida por um soprador de ar central, conectado por mangueiras e pedras porosas em cada aquário.

As pós-larvas passaram uma semana de adaptação no sistema de produção em água branca e foram alimentadas com ração controle, antes da oferta da dieta experimental para que ocorresse ambiência dos animais ao sistema. O arraçoamento realizou-se seis vezes ao dia às 08:00, 10:00, 12:00, 14:00, 16:00 e 18:00 horas, sendo a saciedade aparente.

Foram avaliados diariamente os parâmetros físico-químicos da água: temperatura, $\mathrm{pH}$, condutividade elétrica e oxigênio dissolvido, monitorados com auxílio de uma sonda multiparâmetro YSI profissional. O sifonamento para remoção de restos de ração e feses foi realizado às 07:30 e 18:30 antes da primeira e após a última alimentação. Durante todo o período experimental foram mantidos os parâmetros de qualidade da água, estando dentro da faixa de conforto para a espécie em estudo, com valores médios de temperatura $26.9 \pm 0,5^{\circ} \mathrm{C}$, oxigênio dissolvido $4.0 \pm 0,7 \mathrm{mg} / \mathrm{L}$, condutividade $170.1 \pm 46,6 \mu \mathrm{S} / \mathrm{cm}, \mathrm{pH} 7.2 \pm 0,5$ permaneceram dentro das recomendações (Sibaúba-Tavares 1995; Dias et al., 2011).

Ao final do experimento os peixes foram mantidos em jejum por 24 horas e posteriormente anestesiados com eugenol, diluído em álcool etílico na proporção de $1 \mathrm{ml} /$ eugenol/10ml de álcool 98\%, para a retirada de fígado e intestino para análises histológicas.

Foram avaliados o peso final; comprimento final; ganho em peso = (peso final - peso inicial); ganho de peso diário $=($ ganho de peso/dias $) ;$ taxa de crescimento especifico $=100 \mathrm{x}[(\mathrm{In}$ peso final - In peso inicial $) /$ número dedias $]$; conversão alimentar aparente $=$ consumo de alimento/ganho em peso em dias; taxa de retenção protéica $=[($ peso final $\times$ proteína corporal final) - (peso inicial×proteína inicial corporal)/proteína total ingerida]×100; sobrevivência; índice vesserossomatico $=($ peso das visceras $* 100 /$ peso total $) ;$ índice hepatossamático $=($ peso do fígado * $100 /$ peso total $)$ e comprimento do intestino. As análises da composição bromatológica de umidade, proteína bruta, lipídeos e cinzas foram realizadas através da metodologia descrita por (Silva \& Queiroz, 2002).

Foram coletadas amostras do intestino e fígado de cinco peixes de cada repetição para cada tratamento, as amostras foram fixadas em formol tamponado por 48 horas. Posteriormente, foram lavadas em água corrente por duas horas e desidratada em etanol. Utilizou-se metodologia de rotina de acordo com Cargnin-Ferreira \& Sarasquete Reiriz, (2008), para a inclusão em parafina a $58^{\circ} \mathrm{C}$, utilizou-se xilol como líquido intermediário. 
Após inclusão do material em parafina, os blocos resultantes foram cortados em micrótomo. Os cortes, com espessura de $5 \mu \mathrm{m}$, foram estirados e recolhidos em banho termostático a $52^{\circ} \mathrm{C}$ e dispostos sobre as lâminas. Os cortes foram desparafinizados conforme a metodologia de rotina e corados com a técnica de Cargnin-Ferreira \& Sarasquete Reiriz, (2008). Para o cálculo do hepatócito média da área nuclear para cada fotografia foi calculado por planimétrica do perímetro e diâmetro segundo (Strüssmann et al., 1990).

A obtenção das medidas de altura e altura padrão das vilosidades corresponderam à distância do ápice das vilosidades até o início da camada muscular e do ápice das vilosidades até o término da serosa, respectivamente; a largura das vilosidades e a espessura do epitélio.

Os resultados foram submetidos à análise de variância One-Way ANOVA e homogeneidade as médias dos tratamentos foram comparados pelo teste de Tukey, ao nível de 5\% de probabilidade.

\section{Resultados e Discussão}

Os resultados de desempenho zootécnico não apresentaram valores significativos $(\mathrm{P}<0,05)$ entre os níveis de inclusão de probiótico do gênero Bacillus (Tabela 2). Resultado semelhante ao relatado por Batista et al. (2016), onde o ganho de peso, índices de crescimento diário e conversão alimentar não foram afetados.

Tabela 2. Parâmetros de desempenho produtivo de pós-larvas de tilápia do Nilo (Oreochromis niloticus) alimentados diferentes níveis de probióticos.

\begin{tabular}{|c|c|c|c|c|c|c|c|}
\hline \multirow[b]{2}{*}{ Variável } & \multicolumn{7}{|c|}{ Níveis de probióticos (g/100g) } \\
\hline & Controle & 0,02 & 0,04 & 0,06 & 0,08 & 0,10 & Valor-p \\
\hline${ }^{1} \mathbf{P I}(\mathrm{g})$ & $0,05 \pm 0,01$ & $0,05 \pm 0,01$ & $0,05 \pm 0,01$ & $0,05 \pm 0,01$ & $0,05 \pm 0,01$ & $0,05 \pm 0,01$ & Ns \\
\hline${ }^{2} \mathbf{P F}(\mathrm{g})$ & $11,88 \pm 071$ & $12,52 \pm 0,52$ & $11,47 \pm 0,40$ & $13,63 \pm 2,42$ & $11,50 \pm 0,68$ & $12,22 \pm 0,48$ & Ns \\
\hline${ }^{3} \mathbf{G P}(\mathrm{g})$ & $11,83 \pm 0,71$ & $12,47 \pm 0,52$ & $11,42 \pm 0,40$ & $13,58 \pm 2,42$ & $11,44 \pm 0,67$ & $12,17 \pm 0,48$ & Ns \\
\hline${ }^{4}$ GPD $\left(\right.$ g.dia $\left.{ }^{-1}\right)$ & $0,25 \pm 0,01$ & $0,26 \pm 0,01$ & $0,24 \pm 0,01$ & $0,28 \pm 0,05$ & $0,24 \pm 0,01$ & $0,25 \pm 0,01$ & Ns \\
\hline${ }^{5}$ CAA & $0,98 \pm 0,09$ & $0,92 \pm 0,08$ & $1,03 \pm 0,01$ & $0,98 \pm 0,05$ & $0,96 \pm 0,08$ & $0,95 \pm 0,02$ & Ns \\
\hline${ }^{6} \mathrm{TCE}$ & $24,64 \pm 1,48$ & $25,98 \pm 1,07$ & $23,78 \pm 0,83$ & $28,30 \pm 5,05$ & $23,84 \pm 1,41$ & $25,35 \pm 1,01$ & Ns \\
\hline${ }^{7} \mathbf{S}(\%)$ & $65,00 \pm 1,82$ & $66,50 \pm 3,11$ & $67,00 \pm 1,41$ & $60,25 \pm 11,70$ & $69,25 \pm 0,50$ & $67,75 \pm 0,96$ & Ns \\
\hline${ }^{8} \mathrm{CT}(\mathrm{cm})$ & $7,10 \pm 0,10$ & $7,12 \pm 0,15$ & $7,02 \pm 0,15$ & $7,36 \pm 0,62$ & $6,95 \pm 0,14$ & $7,07 \pm 0,14$ & Ns \\
\hline${ }^{9} \mathrm{CI}(\mathrm{cm})$ & $51,95 \pm 6,79$ & $46,53 \pm 8,77$ & $49,78 \pm 6,15$ & $47,25 \pm 7,02$ & $48,98 \pm 7,56$ & $51,70 \pm 6,91$ & Ns \\
\hline${ }^{10}$ IVS & $8,32 \pm 1,53$ & $6,79 \pm 1,95$ & $7,59 \pm 2,44$ & $7,58 \pm 2,97$ & $7,47 \pm 1,91$ & $7,71 \pm 2,37$ & Ns \\
\hline${ }^{11}$ IHS & $1,57 \pm 0,48$ & $1,20 \pm 0,25$ & $1,28 \pm 0,45$ & $1,25 \pm 0,42$ & $1,47 \pm 0,34$ & $1,53 \pm 0,42$ & Ns \\
\hline
\end{tabular}

Valores expressos em média \pm desvio padrão; Valores seguidos por letra diferente, na mesma linha, indicam diferença significativa pelo teste de Tukey $(\mathrm{P}<0,05)$. ns - não significativo. ${ }^{1} \mathrm{PI}$ - peso inicial; ${ }^{2} \mathrm{PF}$ - peso final médio; ${ }^{3} \mathrm{GP}$ - ganho de peso; ${ }^{4} \mathrm{GPD}$ - ganho em peso diário; ${ }^{5} \mathrm{CAA}$ - conversão alimentar aparente; ${ }^{6} \mathrm{TCE}$ - taxa de crescimento específico; ${ }^{7} \mathrm{~S}$ - sobrevivência; ${ }^{8} \mathrm{CT}$ - comprimento total; ${ }^{9} \mathrm{CI}$ - comprimento do intestino; ${ }^{10} \mathrm{IVS}$ - índice viscerossomatico; ${ }^{11} \mathrm{IHS}$ - índice hepatossomatico. Fonte: Autores.

Dias et al. (2011) ao realizarem um estudo de desempenho com pós-larvas de matrinxã, Brycon amazonicus, observaram que não houve uma melhora entre ganho de peso e sobrevivência entre o tratamento controle comparando com os animais alimentados com dietas suplementadas com probióticos

O desenvolvimento de animas mantidos em boas condições de manejo dificilmente é influenciado pela ação de dietas contendo probióticos (Lima et al., 2003), tendo em vista que o contado de microrganismos é mínimo por não 
possuir tempo hábil para colonizar o trato intestinal, dos peixes que consumiram ração com probióticos apresentando ganho de peso equivalente aos que receberam rações sem a inclusão de probiótico (Ferreira et al., 2015).

Para índices de desempenho observados no presente trabalho, corrobora o estudo realizado por Carvalho et al. (2011), onde utilizou probióticos na ração, e relata não ter observado influência na sobrevivência, conversão alimentar aparente bem como o índice hepatossomático de tilápia do Nilo. Schwarz et al. (2010) ao trabalharem com dietas contendo manoligossacarídeos para juvenis de tilápia do Nilo, não observaram efeito dos níveis de inclusão sobre o ganho de peso, consumo de ração, índice hepatossomático e rendimento de carcaça.

Com relação à composição da carcaça de tilápia do Nilo, não apresentou diferenças para proteína, umidade, lipídio e cinzas ( $p>0,05)$ (Tabela 3).

Tabela 3. Composição centesimal de pós-larvas de tilápia do Nilo (Oreochromis niloticus) alimentados diferentes níveis de probióticos.

\begin{tabular}{|c|c|c|c|c|c|c|c|}
\hline \multirow[b]{2}{*}{ Variável } & \multicolumn{6}{|c|}{ Níveis de probióticos (g/100g) } & \multirow[b]{2}{*}{ Valor-p } \\
\hline & Controle & 0,02 & 0,04 & 0,06 & 0,08 & 0,10 & \\
\hline${ }^{1} \mathbf{U M}(\%)$ & $77,78 \pm 0,96$ & $77,58 \pm 0,59$ & $77,62 \pm 0,69$ & $77,58 \pm 0,90$ & $77,47 \pm 0,43$ & $77,70 \pm 0,46$ & ns \\
\hline${ }^{2} \mathrm{~PB}(\%)$ & $14,89 \pm 0,98$ & $14,61 \pm 0,45$ & $14,72 \pm 0,29$ & $14,49 \pm 0,74$ & $15,04 \pm 0,61$ & $14,66 \pm 0,40$ & ns \\
\hline${ }^{3} \mathbf{P L}(\%)$ & $4,01 \pm 0,51$ & $4,16 \pm 0,44$ & $4,16 \pm 0,57$ & $4,25 \pm 0,90$ & $3,92 \pm 0,39$ & $3,90 \pm 0,61$ & ns \\
\hline${ }^{4} \mathrm{CZ}(\%)$ & $0,40 \pm 0,03$ & $0,39 \pm 0,03$ & $0,38 \pm 0,01$ & $0,43 \pm 0,02$ & $0,41 \pm 0,02$ & $0,40 \pm 0,01$ & ns \\
\hline
\end{tabular}

Valores expressos em média \pm desvio padrão; Valores seguidos por letra diferente, na mesma linha, indicam diferença significativa pelo teste de Tukey $(\mathrm{p}<0,05)$. ns - não significativo. ${ }^{1} \mathrm{UM}$ - umidade; ${ }^{2} \mathrm{~PB}$ - proteína bruta; ${ }^{3} \mathrm{LP}$ - lipídio; ${ }^{4} \mathrm{CZ}$ - cinzas. Fonte: Autores.

Asaduzzaman et al. (2018) avaliando a suplementação de bactérias probióticas do gêneros Bacillus sp., Alcaligenes sp. Shewanella sp, sobre a composição química dos músculos de juvenis de cyprinus da espécie $T$. tambroides, não observaram efeitos positivos, pois os resultados não diferiram $(\mathrm{p}<0,05)$ entre os grupos tratados e o grupo controle.

Para as variáveis estudadas no intestino (Figura 1), a altura dos vilos, não proporcionou diferenças significativas entre os grupos ( $>0,05)$ (Tabela 4). Entretanto a largura dos vilos e espessura da túnica, apresentaram melhores respostas nos níveis de inclusões mais elevado de probióticos $(0,08$ e $0,10 \mathrm{~g})$, promovendo uma melhora na saúde intestinal das pós-larvas de tilápia do Nilo. 
Figura 1. Corte histológico do intestino de pós-larvas de tilápia do Nilo (Oreochromis niloticus) alimentados com diferentes níveis de probióticos. Legenda: A) corte histológico do intestino; B) medições realizadas no corte histológico do intestino; C) espessura da túnica; D) altura dos vilos; e E) largura dos vilos.

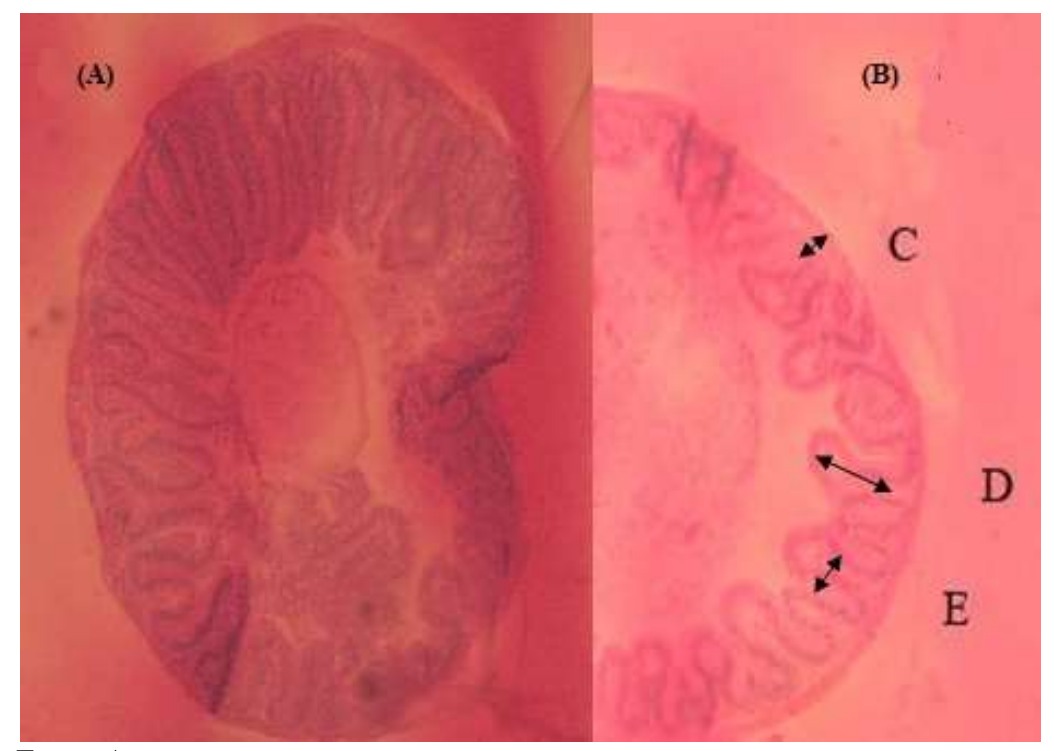

Fonte: Autores.

Tabela 4. Histologia dos intestinos de pós-larvas de tilápia do Nilo (Oreochromis niloticus) alimentados diferentes níveis de probióticos.

\begin{tabular}{llllllll}
\hline \multirow{2}{*}{ Variável } & \multicolumn{7}{c}{ Níveis de probióticos (g/100g) } \\
\cline { 2 - 7 } & Controle & 0,02 & 0,04 & 0,06 & 0,08 & 0,10 & Valor-p \\
\hline${ }^{\mathbf{1}} \mathbf{A V}$ & $141,7 \pm 41,4$ & $143,9 \pm 34,8$ & $142,2 \pm 43,5$ & $145,2 \pm 63,7$ & $120,9 \pm 41,4$ & $122,5 \pm 28,3$ & $\mathrm{~ns}$ \\
${ }^{2} \mathbf{L V}$ & $63,2 \pm 17,1 \mathrm{a}$ & $61,7 \pm 10,7 \mathrm{a}$ & $58,5 \pm 11,9 \mathrm{a}$ & $53,2 \pm 14,4 \mathrm{ab}$ & $44,5 \pm 11,2 \mathrm{bc}$ & $41,0 \pm 7,7 \mathrm{c}$ & $* 0,00$ \\
${ }^{3} \mathbf{E T}$ & $49,8 \pm 9,3 \mathrm{a}$ & $48,9 \pm 12,0 \mathrm{ab}$ & $42,8 \pm 9,7 \mathrm{ab}$ & $40,8 \pm 11,0 \mathrm{~b}$ & $30,9 \pm 8,6 \mathrm{c}$ & $27,7 \pm 7,2 \mathrm{c}$ & $* 0,00$ \\
\hline
\end{tabular}

Médias seguidos por letra diferente, na mesma linha, indicam diferença significativa pelo teste de Tukey $(\mathrm{P}<0,05)$. ns - não significativo. ${ }^{*}$ - significativo. ${ }^{1} \mathrm{AV}$ - altura dos vilos; ${ }^{2} \mathrm{LV}$ - largura dos vilos; ${ }^{3} \mathrm{ET}$ - espessura da túnica. Fonte: Autores.

Segundo Batista et al. (2016) trabalhando com suplementação de probióticos na ração para a espécie Solea senegelensis, verificaram que no intestino um aumento na área da secção, do comprimento das vilosidades e da largura dos vilos, indicando um aumento da área superficial demonstrando uma melhora na capacidade de absorção dos nutrientes. Rocha et al. (2016), explicam que o probiótico Bacillus subtilis como proteção de forma antimicrobiana para os vilos e superfícies absortivas contra microrganismos patógenos em peixes, além, de auxiliarem na digestão e na absorção intestinal.

A análise histológica do sistema digestivo é considerada um bom indicador do estado nutricional do peixe (Caballeiro et al., 2004). O intestino possui importância na digestão e absorção de nutrientes dos alimentos, monitorização destes órgãos é considerado necessário (Roberts, 1989). Existe vários métodos de análise histológica que são utilizados, na maioria das vezes sistema de pontuação semiquantitativo, método histoquímica e imuno-histoquímica, enquanto os métodos estereológicos são raramente utilizados (Rašković et al. 2011).

Observou-se melhora na saúde intestinal dos pós larvas de tilápia do Nilo naqueles que receberam níveis de

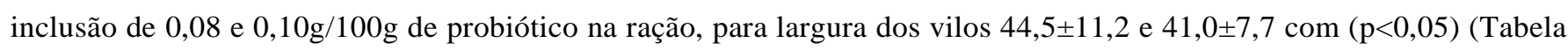
5). Para a espessura da túnica foi observado que as camadas serosas e musculares não apresentaram patologias. 
Avaliando o hepatócito de pós-larvas de tilápia do Nilo (Figura 2), observou-se que não apresentou esteatose e necrose hepática no fígado dos peixes no experimento realizado com dietas suplementadas com bactérias probióticas do gênero Bacillus, entre as variáveis estudadas foram perímetro, área e volume do núcleo, onde não houve diferenças entre os grupos tratados em relação ao grupo controle ( $p>0,05)$ (Tabela5).

Figura 2. Corte histológico à $5 \mu$ do fígado de pós-larva tilápia do Nilo, demostrando as medidas perímetro, área e volume do núcleo do hepatócito.

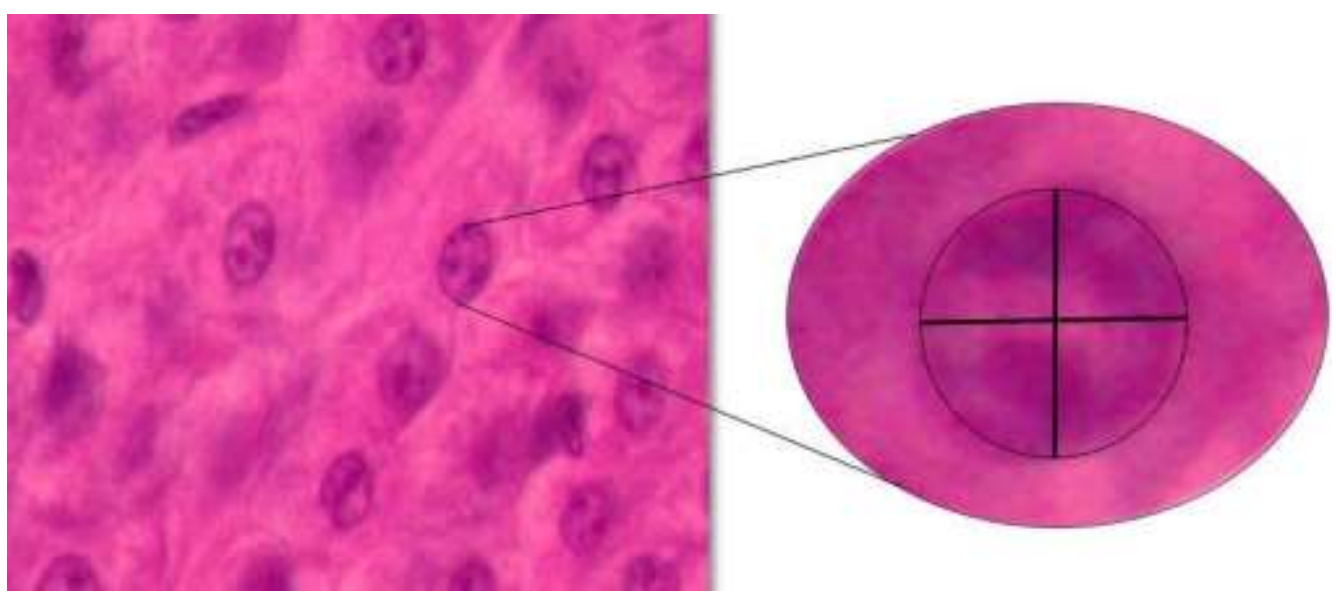

Fonte: Autores.

Tabela 5. Histologia dos fígados de pós-larvas de tilápia do Nilo (Oreochromis niloticus) alimentados diferentes níveis de probióticos.

\begin{tabular}{|c|c|c|c|c|c|c|c|c|}
\hline \multirow[b]{2}{*}{ Variável } & \multicolumn{6}{|c|}{ Níveis de probióticos $(\mathrm{g} / \mathbf{1 0 0 g})$} & & \multirow[b]{2}{*}{ Valor-p } \\
\hline & Controle & 0,02 & 0,04 & 0,06 & 0,08 & 0,10 & & \\
\hline$\overline{1} \mathbf{P N}$ & $9,5 \pm 0,4$ & $10,0 \pm 1,4$ & $9,5 \pm 0,3$ & $9,6 \pm 0,2$ & $9,6 \pm 0,2$ & $9,5 \pm 0,2$ & ns & \\
\hline${ }^{2} \mathbf{A} \mathbf{N}$ & $22,7 \pm 2,3$ & $23,9 \pm 1,8$ & $22,8 \pm 1,8$ & $23,0 \pm 1,2$ & $23,4 \pm 1,3$ & $22,7 \pm 1,4$ & ns & \\
\hline${ }^{3} \mathbf{V N}$ & $56,9 \pm 8,3$ & $61,7 \pm 6,8$ & $57,5 \pm 6,8$ & $58,1 \pm 4,7$ & $59,6 \pm 5,0$ & $57,0 \pm 5,2$ & ns & \\
\hline
\end{tabular}

Médias seguidos por letra diferente, na mesma linha, indicam diferença significativa pelo teste de Tukey $(\mathrm{P}<0,05)$.

ns - não significativo. ${ }^{*}$ - significativo. ${ }^{1} \mathrm{PN}$ - perímetro do núcleo $(\mathrm{PN}) ;{ }^{2} \mathrm{AN}$ - área do núcleo; ${ }^{3} \mathrm{VN}$ - volume do núcleo. Fonte: Autores.

As alterações hepáticas no fígado são facilmente identificadas quando a dietas não supri as exigências nutricional dos peixes, sendo as mudanças mais comum: vascularização, gordura no fígado e necrose hepática. Bolla et al. (2011), afirma que mudanças no fígado revela informações do estado nutricional dos peixes. Características estruturais dentro dos hepatócitos tem relação direta com os teores de proteínas não-cromossômica dos núcleos (Strüssmann et al., 1990).

Proteínas provenientes de alimentos ou gordura podem modificar as estruturas do fígado, no entanto o aumento do tamanho do núcleo revela alterações no metabolismo ocasionando necroses hepáticas ou esteatose (Caballero et al., 2004; Raskovic et al., 2011). Como o estudo realizado não houve anormalidade no núcleo do hepatócito quando ofertado a dieta com probióticos do gênero Bacillus $(\mathrm{p}>0,05)$.

Segundo Raskovic et al. (2016) os hepatócitos podem conter vacúolos lipídicos pequenos e grandes, ou até mesmo vacúolos irregulares. No presente estudo observou-se pequenos vacúolos lipídicos, onde esses não alteraram os parâmetros estuda para fígado. 


\section{Conclusão}

Apesar de, os diferentes níveis de inclusão de probiótico do gênero Bacillus na dieta não influencia no desempenho zootécnico da tilápia do Nilo, recomenda-se a inclusão de $0,08 \mathrm{~g} / \mathrm{kg}$ de probiótico do gênero Bacillus por apresentar melhora na saúde intestinal das pós-larvas de tilápia do Nilo.

Devido a isto, e como sugestões para trabalhos futuros, deve-se estudar quais as bactérias mais importantes para criação de peixes e avaliar se é viável ou não utilizar esses produtos, além disso, é importante realizar análise bacteriológica do intestino e da água.

\section{Agradecimentos}

Os autores agradecem à Universidade Estadual do Oeste do Paraná (UNIOESTE) e ao Grupo de Estudos de manejo na Aquicultura (Gemaq), também ao Instituto Federal do Paraná (IFPR) por suas contribuições, em relação a infraestrutura laboratorial, que foram essenciais para o desenvolvimento deste estudo. O agradecimento se estende à CAPES pela cessão da bolsa de estudos na modalidade Demanda Social.

\section{Referências}

Asaduzzaman, M.; Sofia, E.; Shakil, A.; Haque, N. F.; Khan, M. N. A.; Ikeda, D. \&Abol-Munafi, A. B. 2018.Host gut-derived probiotic bacteria promotehypertrophic muscle progression and upregulate growth-related gene expression of slow-growing MalaysianMahseerTortambroides.AquacultureReports. 9,37-45.

Batista, S.; Medina, A.; Pires, M. A.; Moriñigo, M. A.; Sansuwan, K.; Fernandes, O. M. J.; Valente, L. M. P.\& Ozório, R. O. A. 2016.Innate immune response,intestinal morphology and microbiota changes in Senegalese sole fed plant protein dietswith probiotics or autolysed yeast. Applied microbiology and biotechnology. 100(16): 7223-7238.

Bolla, S.; Nicolaisen, O.; \& Amin, A. 2011. Liver alterations induced by long term feeding on commercial diets in Atlantic halibut (Hippoglossushippoglossus L.) females. Histological and biochemical aspects. Aquaculture. 312(1-4): 117-125.

Caballero, M. J., Izquierdo, M. S., Kjørsvik, E., Fernandez, A. J. \&Rosenlund, G. 2004. Histological alterations in the liver of sea bream, Sparus aurata L., caused by short-or long-term feeding with vegetable oils. Recovery of normal morphology after feeding fish oil as the sole lipid source. JournalofFishDiseases. 27(9): 531-541.

Cargnin-Ferreira, E. \&Sarasquete, C. 2008. Histofisiología de moluscos bivalvos marino (Vol. 31). Editorial CSIC-CSIC Press. 94p.

De Carvalho, J. V.; de Lira, A. D.; Costa, D. S. P.; Moreira, E. L. T.; Pinto, L. F. B.; Abreu, R. D.\&Albinati, R. C. B. 2011. Desempenho zootécnico e morfometria intestinal de alevinos de tilápia-do-Nilo alimentados com" Bacillus subtilis" ou mananoligossacarídeo. Revista Brasileira de Saúde e Produção Animal. 12(1).

Cavalheiro, A. C. M.; Castro, M. L. S.; EINHARDT, M.; Pouey, J. L. O. F.; Piedras, S. N. \& Xavier, E. G. 2014. Microingredientes utilizados em alimentação de peixes em cativeiro-Revisão. Revista Portuguesa de Ciências Veterinárias.109: 11-20.

Cornélio, F. H. G.; Cargnin-Ferreira, E.; Borba, M. R. D.; Mouriño, J. L. P.; Fernandes, V. A. G. \&Fracalossi, D. M. 2013. Crescimento, digestibilidade e resistência à infecção por patógeno em tilápia-do-nilo alimentada com probióticos. Pesquisa Agropecuária Brasileira. 48(8): 863-870.

Dawood, M. A. \& Koshio, S. 2016. Recent advances in the role of probiotics and prebiotics in carp aquaculture: a review. Aquaculture. 454: 243-251.

De Melo Lima, V. M.; Júnior, A. F. C.; Scheidt, G. N.; Silva, E. C. S. E. \&Portella, A. C. F. 2018. Probiotics in Aquaculture Review: Current Status and Application in Tambaqui Cultivation (Colossoma macropomum). International Journal of Advanced Engineering Research and Science. 5(5): 237460 .

Dias, D. D. C.; Corrêa, C. F.; Leonardo, A. F. G.; Tachibana, L.; Romagosa, E. \&Ranzani-Paiva, M. J. T. 2011. Probiótico na larvicultura de matrinxã, Bryconamazonicus. ActaScientiarum. Animal Sciences. 33(4): 365-368.

Doroteo, A. M.; Pedroso, F. L.; Lopez, J. D. M. \&Apines-Amar, M. J. S. 2018. Evaluation of potential probiotics isolated from saline tilapia in shrimp aquaculture. Aquaculture International. 26(4): 1095-1107.

Dos Santos Júnior, M. M.; de Jesus, G. F. A.; Legarda, E. C.; Mouriño, J. L. P.; Seiffert, W. Q. \& do Nascimento Vieira, F. 2016. Utilização comparativa de enrofloxacino, probiótico (Lactobacilus plantarum) e propionato de sódio na larvicultura de camarão branco do pacífico. Arquivos de Ciências Veterinárias e Zoologia da UNIPAR. 19(3). 
Ferreira, A. H. C.; Brito, J. M. D.; Lopes, J. B.; Santana Júnior, H. A. D.; Batista, J. M. M.; Silva, B. R. \& Amorim, I. L. D. S. 2015. Probiótico na alimentação de pós-larvas de tilápias-do-nilo submetidas a desafio sanitário. Revista Brasileira de Saúde e Produção Animal. 16(2):430-439.

Fuller, Afrc. R. 1989. Probiotics in man and animals. Journal of applied bacteriology. 66(5): 365-378.

Hayashi, C.; Boscolo, W. R.; Soares, C. M.; Boscolo, V. R. \&Galdioli, E. M. 1999. Uso de diferentes graus de moagem dos ingredientes em dietas para a tilápia-do-Nilo (Oreochromis niloticus L.) na fase de crescimento. ActaScientiarum. Animal Sciences. 21, 733-737.

Ibrahem, M. D 2015. Evolução dos probióticos no mundo aquático: efeitos potenciais, a situação atual no Egito e as perspectivas recentes. Journal of advanced research. 6(6): 765-791.

Iribarren, D.; Dagá, P.; Moreira, M. T. \&Feijoo, G. 2012. Potential environmental effects of probiotics used in aquaculture. Aquaculture international. 20(4): $779-789$.

Kesarcodi-Watson, A.; Kaspar, H.; Lategan, M. J. \& Gibson, L. 2008. Probiotics in aquaculture: the need, principles and mechanisms of action and screening processes. Aquaculture. 274(1): 1-14.

Lazado, C. C. \&Caipang, C. M. A. 2014. Mucosal immunity and probiotics in fish. Fish \& shellfish immunology. 39(1): 78-89.

Lazado, C. C. \&Caipang, C. M. A. 2014. Atlantic cod in the dynamic probiotics research in aquaculture. Aquaculture. 424, 53-62.

Li, X.; Ringø, E.; Hoseinifar, S. H.; Lauzon, H. L.; Birkbeck, H. \& Yang, D. 2019. The adherence and colonization of microorganisms in fish gastrointestinal tract. Reviews in Aquaculture. 11(3): 603-618.

Lima, A. C. F. D.; Pizauro Júnior, J. M.; Macari, M. \& Malheiros, E. B. 2003. Efeito do uso de probiótico sobre o desempenho e atividade de enzimas digestivas de frangos de corte. Revista Brasileira de Zootecnia. 32(1): 200-207.

Linh, N. T. H.; Sakai, K. \&Taoka, Y. 2018. Screening of lactic acid bacteria isolated from fermented food as potential probiotics for aquacultured carp and amberjack. Fisheries science. 84(1): 101-111.

Manzano, M.; Iacumin, L.; Giusto, C.; Cecchini, F.; Patthey, C.; Fontanillas, R. \&Comi, G. 2012. Utilization of denaturing gradient gel electrophoresis (DGGE) to evaluate the intestinal microbiota of brown trout Salmo trutta fario. Journal of Veterinary Science \& Medical Diagnosis. 1(2).

Marengoni, N. G.; Weiss, L. A.; Albuquerque, D. M. \& Moura, M. C. 2015. Influência de probióticos na prevalência parasitária e níveis de glicose e cortisol em tilápia do Nilo. Archivos de zootecnia. 64(245): 63-69.

Mello, H. D.; Moraes, J. R.; Niza, I. G.; Moraes, F. R. D.; Ozório, R. O.; Shimada, M. T. \& Claudiano, G. S. 2013. Efeitos benéficos de probióticos no intestino de juvenis de Tilápia-do-Nilo. Pesquisa Veterinária Brasileira. 33(6): 724-730.

National Research Council. 2011. Nutrient requirements of fish and shrimp. National academies press.

Nayak, S. K. 2010. Probiotics and immunity: a fish perspective. Fish \& shellfish immunology. 29(1): 2-14.

Newaj-Fyzul, A.; Al-Harbi, A. H. \& Austin, B. 2014. Developments in the use of probiotics for disease control in aquaculture. Aquaculture, 431: 1-11.

Ochoa-Solano, J. L. \& Olmos-Soto, J. 2006. The functional property of Bacillus for shrimp feeds. Food microbiology. 23(6): 519-525.

Rašković, B.; Čičovački, S.; Ćirić, M.; Marković, Z. \&Poleksić, V. 2016. Integrative approach of histopathology and histomorphometry of common carp (Cyprinus carpio L.) organs as a marker of general fish health state in pond culture. Aquaculture Research. 47(11): $3455-3463$.

Rašković, B. S.; Stanković, M. B.; Marković, Z. Z. \&Poleksić, V. D. 2011. Histological methods in the assessment of different feed effects on liver and intestine of fish. Journal of Agricultural Sciences (Belgrade). 56(1): 87-100.

Roberts, R. J. 1989. Fish Pathology (2 eds). Londres: BailliereTindall, Inglaterra . 391 pp.

Rocha, P.; Barros, M. E. \& Evêncio-Neto, J. 2016. Análise morfométrica da parede intestinal e dinâmica de mucinas secretadas no jejuno de frangos suplementados com probiótico Bacillus subtilis cepa C3102. Pesquisa Veterinária Brasileira. 36(4): 312-316.

Sado, R. Y.; de Almeida Bicudo, Á. J. \&Cyrino, J. E. P. 2014. Hematology of juvenile pacu, Piaractus mesopotamicus (Holmberg, 1887) fed graded levels of mannan oligosaccharides (MOS). Latin American Journal of Aquatic Research. 42(1): 30-39.

Sahu, M. K.; Swarnakumar, N. S.; Sivakumar, K., Thangaradjou, T. \& Kannan, L. 2008. Probiotics in aquaculture: importance and future perspectives. Indian journal of microbiology. 48(3): 299-308.

Schwarz, K. K.; Furuya, W. M.; Natali, M. R. M.; Michelato, M. \&Gualdezi, M. C. 2010. Mananoligossacarídeo em dietas para juvenis de tilápias do Nilo. ActaScientiarum. Animal Sciences. 32(2): 197-203. 
Research, Society and Development, v. 10, n. 7, e51810717032, 2021

(CC BY 4.0) | ISSN 2525-3409 | DOI: http://dx.doi.org/10.33448/rsd-v10i7.17032

Sibaúba-Tavares, L. H. 1995. Limnologia aplicada à aquicultura. Funep, Jaboticabal. 70.

Silva, D.J.; Queiroz, A. C. 2002. Análise de Alimentos: métodos químicos ebiológicos.(3. ed), Viçosa: UFV.235p.

Strüssmann, C. A. \& Takashima, F. 1990. Hepatocyte nuclear size and nutritional condition of larval pejerrey, Odontesthes bonariensis (Cuvier et Valenciennes). JournalofFishBiology. 36(1): 59-65.

Vieira, J. S.; Logato, P. V. R.; Ribeiro, P. A. P.; Freitas, R. T. F. D. \& Fialho, E. T. 2005. Efeito do processamento do milho sobre o desempenho e composição de carcaça de piaba (Leporinus friderici) criada em tanques-rede. Ciência e Agrotecnologia. 29(2): 453-458. 